\title{
Energy Optimization and Management in a Building Using Clean Energy
}

\author{
HAJJI ABDELGHANI ${ }^{\mathrm{a}}$, LAHLOU YAHYA ${ }^{\mathrm{b}}$, ABBOU AHMED $^{\mathrm{c}}$ \\ ${ }^{\mathrm{a}, \mathrm{c}}$ Department of Electrical Engineering, Mohammed V University of Rabat \\ Mohammadia School of Engineers, MOROCCO \\ ${ }^{b}$ Department of Physics, Ibn Tofail University, Faculty of Sciences, Kenitra, MOROCCO
}

\begin{abstract}
To lower the production of greenhouse gases while covering energy needs, it is necessary to exploit renewable energies in the urban environment and manage energy production and consumption as well.

In this work, we interested in the study of a house using renewable energy sources such as photovoltaic (PV) panels, thermal panels and wind turbines (WT). The energy consumption happens through electrical charges like the refrigerator, the heat pump, the lighting...

The main objective of this work is to change the operating time of secondary loads and to propose an energy management algorithm.

Firstly, we will model the consumption of electrical charges and move the operation of secondary charges to moderate the consumed energy. Finally, we suggested an algorithm to manage and optimize energy production and consumption.

The results show that the displacement of secondary loads reduces over $8.5 \%$ of the energy bill and the suggested algorithm optimizes the operation of the energy production equipment while covering the energy needs of the inhabitants.
\end{abstract}

Key-Words: - Electrical charges, Modeling, Optimization, Algorithm, Energy Management, Wind Turbine, Photovoltaic Panel.

Received: October 12, 2020. Revised: March 22, 2021. Accepted: March 30, 2021. Published: April 9, 2021.

\section{Introduction}

Buildings generate about $25-40 \%$ of greenhouse gas emissions, which are the main determinant of climate change [1]. The energy consumption of a building represents up to $40 \%$ of the total energy consumption, especially in developed countries [2]. To control energy consumption in building and reduce of greenhouse gas, there are several solutions:

- Using of low consumption electrical loads.

- Integration of renewable energies in the buildings.

- Implementation of a smart load management [3].

In order to manage energy as well as possible while ensuring the desired comfort, Ky LE (2008) proposed a real-time load management method based on load shedding according to the power curve authorized [3].
In this work, a real-time load management method is proposed based on load shedding according to the availability of hot water supplied by a solar water heater. In order to reduce the total power consumed in the building, we can shift the operating time of the washing machine and dishwasher to periods when there is the availability of hot water from solar water heaters, which will moderate the power consumed.

The displacement can be done according to several criteria such as the price of $\mathrm{kWh}$, the security or the availability of energy. In this case, the displacement depends on the availability of hot water and solar energy.

On the other hand, to ensure better use of renewable energy resources such as wind and solar energy. Elsied et al (2014) have developed a model using genetic algorithms [4].

In this way, M. Abarkan (2013) proposed a control algorithm developed with the state flow. The switching control system seeks to optimize resources in terms of consumption and storage [5]. 
For our case, we managed the production and consumption of energy in the studied building and we proposed an algorithm that uses an approach that uses the State-flow library of Matlab / Simulink. Our algorithm is compared with the results of M. Abarkan (2013).

In our work, we combined the displacement of secondary loads consumption and the energy management algorithm.

The diagram in Figure 1 below summarizes the objective of our work:

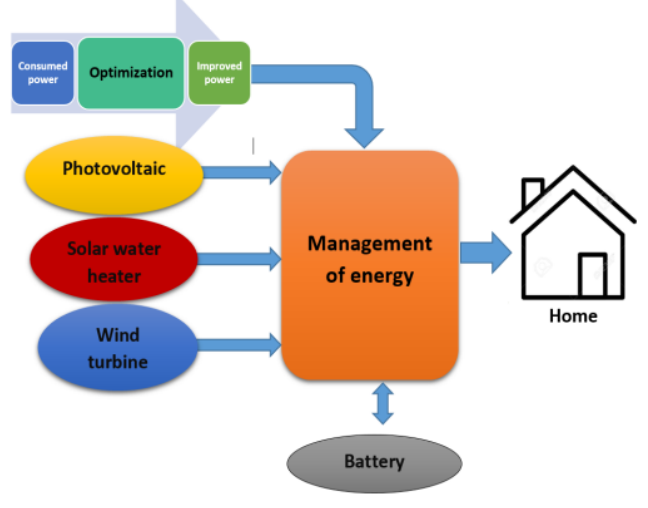

Fig .1. Energy optimization and management

\section{Modeling the Energy Consumption of a House}

\subsection{Equipments}

The studied building is equipped with the following electrical charges:

Table1. Power of electric charges

\begin{tabular}{|c|c|}
\hline Electric charges & Power $(\boldsymbol{W})$ \\
\hline Refrigerator & 150 \\
\hline Washing machine & $2400-80-150$ \\
\hline Dishwasher & $1600-80-1600$ \\
\hline Heat pump & 14823 \\
\hline Electric cooker & 1000 \\
\hline Lighting & 120 \\
\hline Refrigerator & 150 \\
\hline
\end{tabular}

To model the consumption of the electrical loads of the studied building using the Matlab/Simulink software, we was used the power and operating time of each load.

\subsection{Method}

The objective of this part is the modeling of the consumption of the electrical loads using the Matlab/Simulink software.

Let's take the example of the washing machine: The model of the washing machine is shown in Figure 2 with a washing and rinsing power of $80 \mathrm{~W}$, a spinning power of $150 \mathrm{~W}$ and a washing heating power of 2400W [3].

In the same way as the washing machine, we modelled all electric charges and we obtained the following schema:

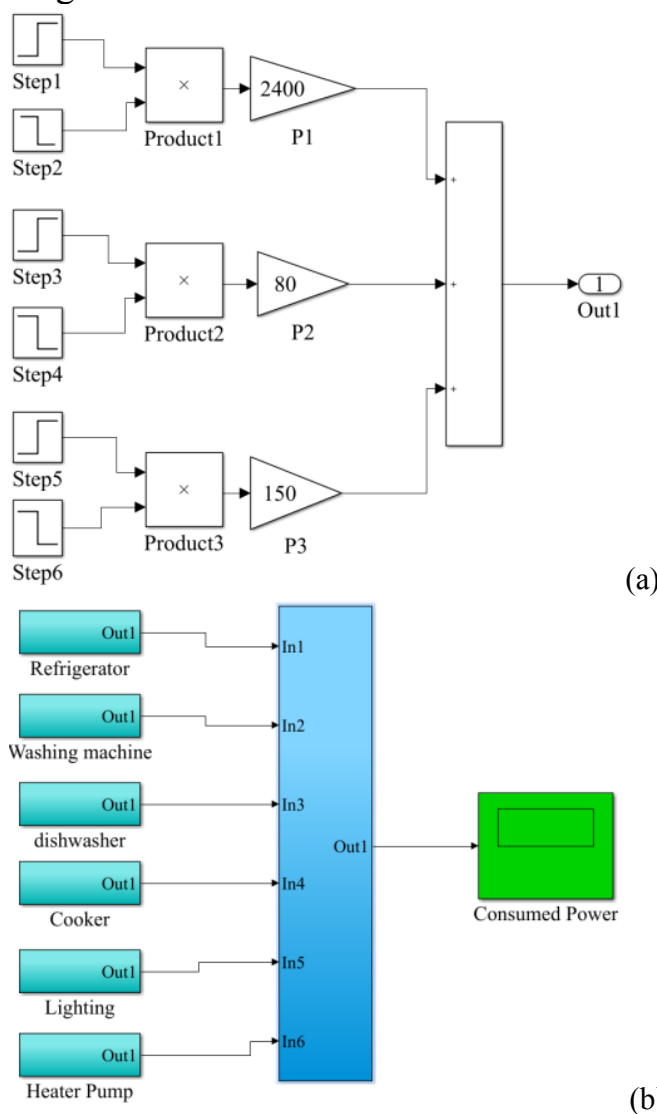

Fig. 2: (a) Washing machine modeling (b) Modeling of electric charges

\subsection{Results and Discussion}

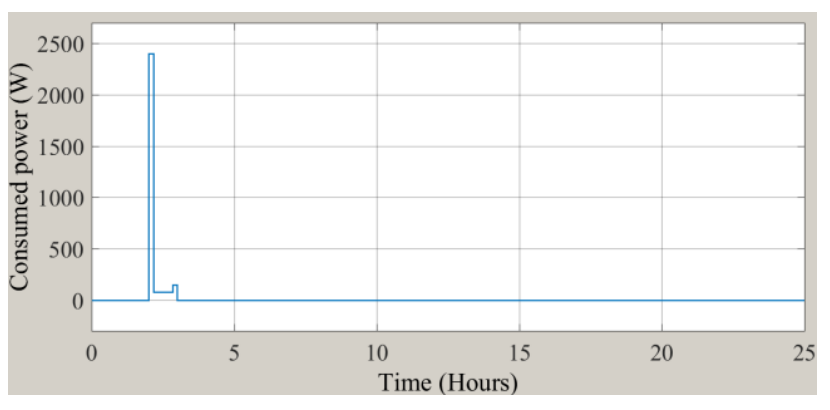

(a) Washing machine modeling 


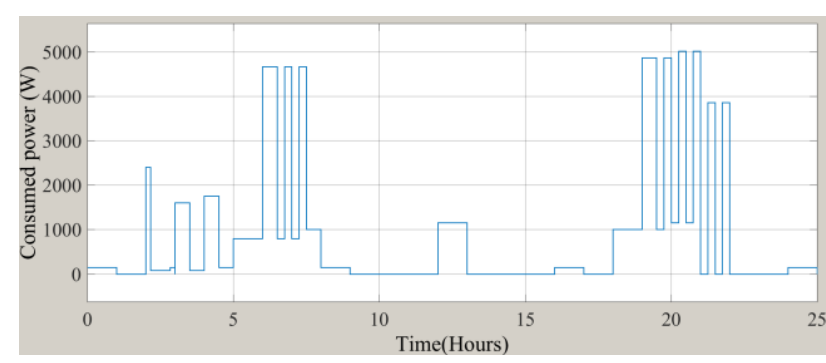

(b) Electric charges modeling

Fig.3: Evolution of the consumed power

For figure .3 (a), we notice that the washing machine consumes a significant power in the first phase (water heating) compared to the other phases. The same goes for Dishwasher.

For figure .3 (b), we notice that there is a significant energy consumed by the heat pump to heat the house.

In the middle of the day, the energy consumption within the house is low, however, PV can produce significant energy. To do this, consider moving the operation of certain electrical charges to optimize the energy consumed.

\section{Optimization of the Energy Consumed in the Building}

\subsection{Equipment and Method}

To optimize the energy consumed in the building under study, the solar water heater is used as a renewable energy source that supplies the washing machine and dishwasher with hot water.

Electric loads can be classified into two main categories:

$\checkmark$ Exclusive loads: They cover the essential needs of the inhabitants and cannot be delayed. Generally, they consume a lot of energy (lighting, heating, cooling).

$\checkmark$ Secondary loads: They correspond to specific needs or to auxiliary functions such as the use of the washing machine, the dishwasher... [7].

In general the shift of operation of the loads (of the washing machine and dishwasher) can be done according to several criteria such as the price per $\mathrm{kWh}$, safety, availability of energy, availability of hot water.In this work, the load shedding is done according to the availability of hot water supplied by a solar water heater.
The accumulation of the consumed energy at time $t_{n}$ is calculated using the following relation:

$$
E_{n}=\sum_{i=1}^{n} P_{i}\left(t_{i}-t_{i-1}\right)
$$

$P_{i}$ : Electric power consumed during the interval $\left[t_{i} ; t_{i-1}\right]$.

After the displacement, the energy consumed at time $t_{n}$ becomes:

$$
E_{n}^{*}=\sum_{i=1}^{n}\left(1-\varepsilon_{i}\right) \cdot P_{i} \cdot\left(t_{i}-t_{i-1}\right)
$$

$\varepsilon_{i}$ : Power reduction coefficient of phase $\mathrm{i}$, it depends on the machine operating phase and the operating period.

The operating period of each device can be divided into three phases and each phase is characterized by a power, an operating time and a reduction coefficient. These characteristics are grouped in the table below:

Table2. Characteristics of Washing machine and Dishwasher

\begin{tabular}{|c|c|c|c|c|}
\hline \multicolumn{2}{|c|}{ Machine } & \multicolumn{3}{c|}{ Operating phases } \\
\cline { 3 - 5 } & $\begin{array}{c}\text { Phase } \\
1\end{array}$ & $\begin{array}{c}\text { Phase } \\
2\end{array}$ & $\begin{array}{c}\text { Phase } \\
3\end{array}$ \\
\hline \multirow{3}{*}{$\begin{array}{c}\text { Washing } \\
\text { machine }\end{array}$} & $\begin{array}{c}\text { Power } \\
(\mathrm{W})\end{array}$ & 2400 & 80 & 150 \\
\cline { 2 - 5 } & $\begin{array}{c}\text { Duration } \\
(\mathrm{min})\end{array}$ & 10 & 30 & 10 \\
\cline { 2 - 5 } Dishwasher & $\varepsilon_{i}(\%)$ & $\mathbf{8 0}$ & 0 & 0 \\
\hline & $\begin{array}{c}\text { Power } \\
(\mathrm{W})\end{array}$ & 1600 & 80 & 1600 \\
\cline { 2 - 5 } & $\begin{array}{c}\text { Duration } \\
(\mathrm{min})\end{array}$ & 30 & 30 & 30 \\
\cline { 2 - 5 } & $\varepsilon_{i}(\%)$ & $\mathbf{8 0}$ & 0 & 0 \\
\hline
\end{tabular}

For washing (laundry or dishes), it has an essential thermal function since $\mathbf{8 0 \%}$ of the energy consumed during a washing cycle is used to heat the water [3].The study building is equipped with a solar water heater that is capable to providing domestic hot water and also provides hot water to the washing machine and dishwasher.

\subsection{Results and Discussion}

From the evolution of the power consumption Fig. 3 and equation (2) we found the evolution of the energy consumed by the electrical loads before and after the displacement is given in figure 4 : 


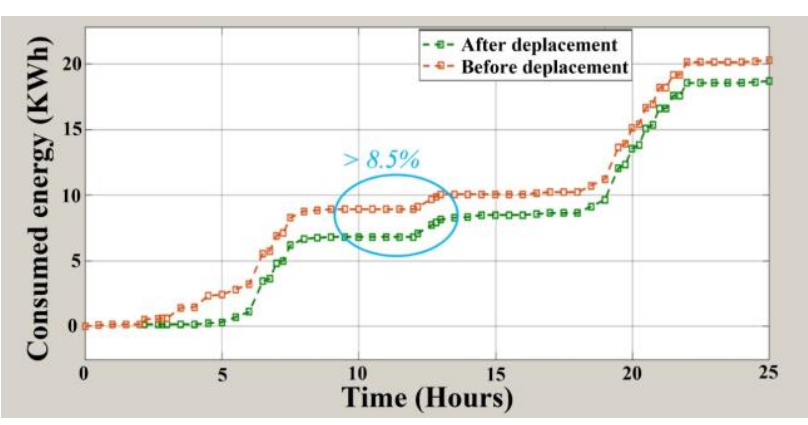

Fig. 4: Evolution of the energy consumed before and after displacement

It is observed that there is a difference in the energy consumption before and after the shift of the operation of the washing machine and the dishwasher.On average, energy consumption can be reduced by $8.5 \%$ by the effect of secondary load displacement and the free availability of hot water. With this action, the energy consumed in the house becomes moderate and has a positive effect on the cost of investment in clean energy equipment.

\section{Energy Management Algorithm}

\subsection{Algorithm}

We used the State-flow tool which allows us to manage constraints. Indeed, State-flow plays the role of supervision unit and instructions generation. This tool presents a user-friendly graphical interface and allows a good interaction with the models used in the global simulations of the bench test [8], [9].

The strategy of switching and controlling the production of PV and wind turbines as well as the management of charge and discharge of the battery is summarized in the following flowchart:

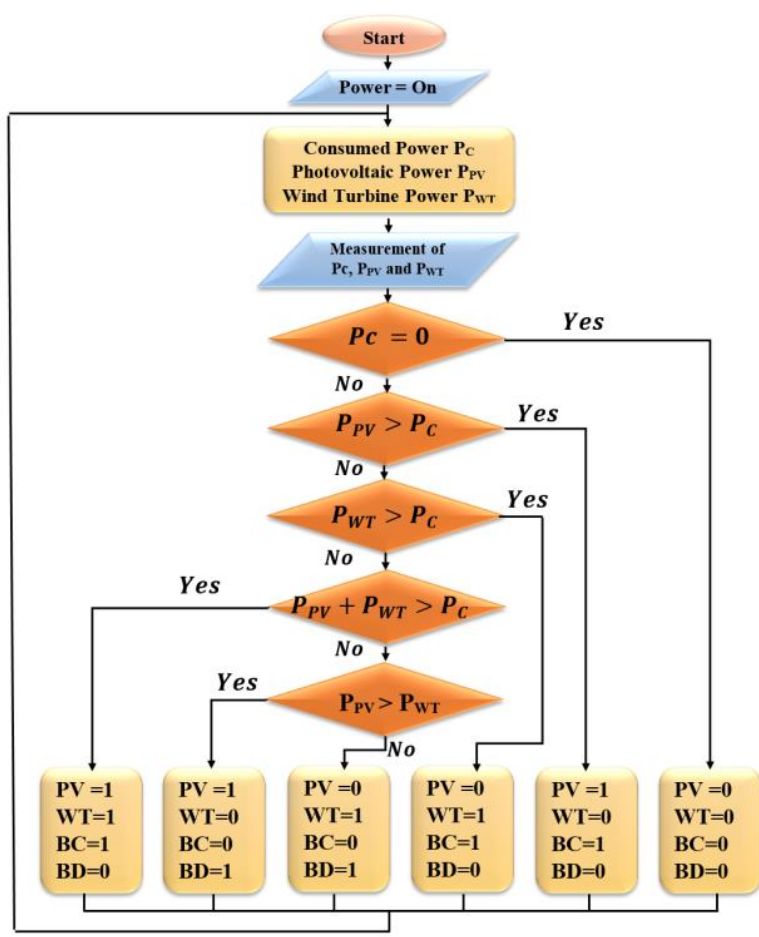

Fig.5: Suggested organization chart

The management of the system complies with the following rules, with the status equal to 1 if activated, and 0 if deactivated. We used the State-flow tool available on Matlab/Simulink which allows to deal with the constraints of the energy management algorithm. Here is the produced program diagram:

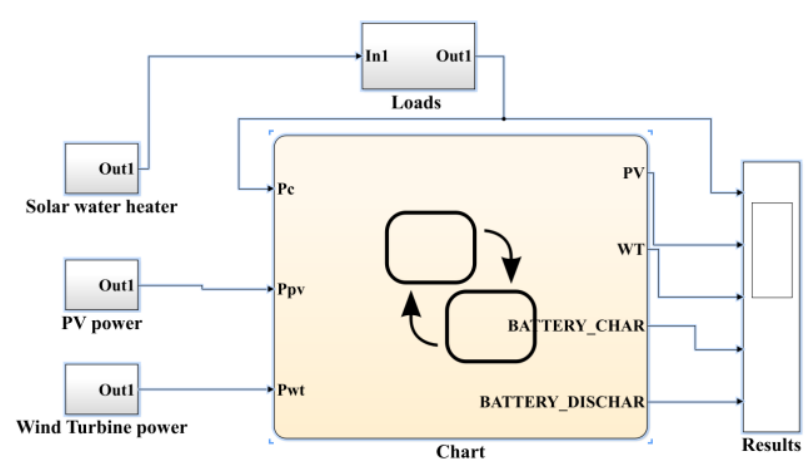

Fig.6: State-flow algorithm diagram

\subsection{Results and Discussion}

Our proposed algorithm is valid for all solar and wind energy profiles, but just to test it, we propose the following two complementary profiles: 


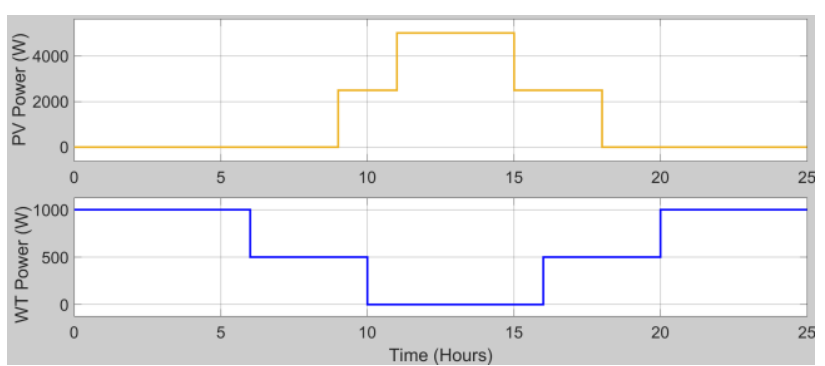

Fig. 7: Proposed profile of the power produced by $P V$ and $W T$

We executed the last program in figure 6 and obtained the evolution of the $\mathrm{P}_{\mathrm{C}}$ power consumption in the studied building and the operating status of PV, WT, battery charge and discharge.

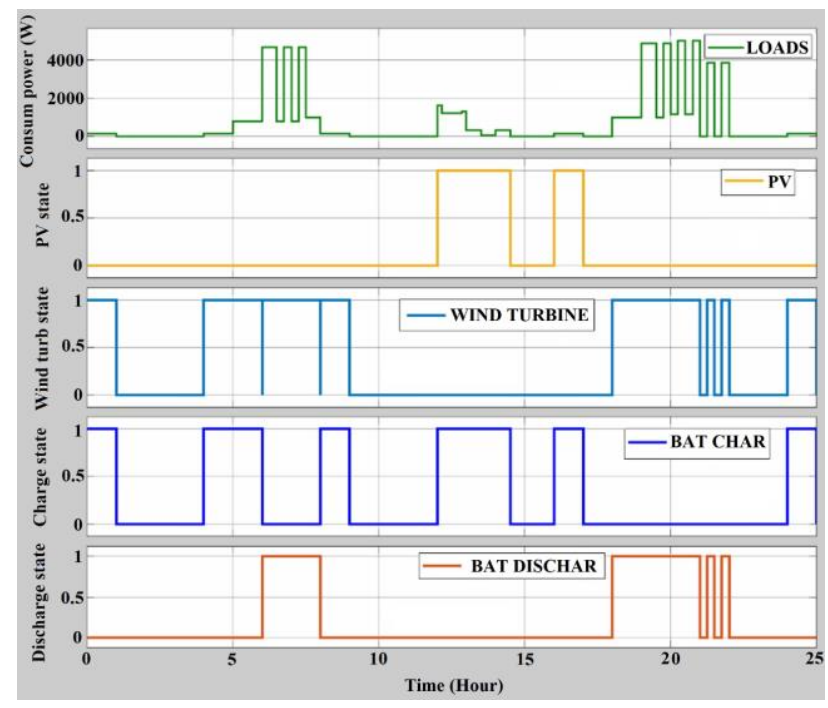

Fig.8: Results of the energy management algorithm

If $\mathrm{Pc}=0$, you must deactivate all the equipment. When $\mathrm{Pc}$ is small than $\mathrm{P}_{\mathrm{PV}}$ we activate the $\mathrm{PV}$ and the rest of the energy is stored in the battery, if $\mathrm{Pc}$ is big than $\mathrm{P}_{\mathrm{PV}}$ and smaller than $\mathrm{P}_{\mathrm{WT}}$ we deactivate the PV and activate the wind turbine and the battery is charged but if $\mathrm{Pc}$ is big than $\mathrm{P}_{\mathrm{PV}}$ and $\mathrm{P}_{\mathrm{WT}}$ on $\mathrm{PV}$ is activated, the wind turbine and the battery are discharged etc.

This energy management technique, for a hybrid system, is implemented under State-flow. Even with a simple set of rules, this control method has proven effective in managing the energy produced by the hybrid system with multiple uses. Because it can manage all of the energy flows in the building, of satisfying the loads.

\section{Conclusion}

Energy efficiency is a set of gestures that optimize energy while keeping the same comfort for the occupants.In this work, we combined the displacement of secondary charges and the suggestion of an energy management algorithm:

By moving the secondary loads, energy consumption can be reduced by $8.5 \%$ of the energy consumed.The proposed algorithm capable of optimizing the operation of energy production and storage equipment while covering the energy needs of the occupants.

The advantage of shifting the consumption in our work is based on the availability of hot water due to solar radiation (renewable energy), whereas for Ky LE [3] the shift is based on the power curve authorized.

The advantage of our algorithm compared to the algorithm of M.Abarkan [5] is that we have added two other cases such as one where there is no energy consumption in the building $\left(\mathrm{P}_{\mathrm{C}}=0\right)$ and a second case where the energy produced by the $\mathrm{PV}$ and the WT exceeds the required power $\left(\mathrm{P}_{\mathrm{PV}}+\mathrm{P}_{\mathrm{WT}}>\mathrm{P}_{\mathrm{C}}\right)$, which allows us to optimize the energy consumption...

The results show that energy management is capable of reducing primary energy consumption, extending the life of energy production equipment, especially the battery (which is too expensive and does not exceed 5 years [10], [11]) and reducing the production of greenhouse gases while covering energy needs and meeting demand.

\section{References:}

[1] R.Vasaturo. "Impact of passive climate adaptation measures and building orientation on the energy demand of a detached lightweight semiportable building" Build. Simul.11 (6), 1163-1177 (2018).

[2] L.Pérez-Lombard. "A review on buildings energy consumption information"'Energy Build. 40(3), 394398 (2008).

[3] Ky LE. "Gestion optimale des consommations d'énergie dans les bâtiments" Thèse de doctorat d'INP Grenoble. Grenoble, France; 2008.

[4] M.Elsied, “ Gestion de l'énergie et optimisation du système multisources basée sur l'algorithme génétique" in: Symposium de Génie Électrique 2014. Cachan, France. 
[5] M.Abarkan and al. Analysis of Energy Consumption for a Bulding using Wind and Solar Energy Sources", Energy Procedia, 2013; Volume 42, Pages 567_576.

[6] Theodosiou, Theodoros \& Papadopoulos, Agis. "The impact of thermal bridges on the energy demand of buildings with double brick wall constructions. Energy and Buildings; 2008. 40. 20832089. 10.1016/j.enbuild.2008.06.006.

[7] Rim.Missaoui and al. "Energy Fluxes optimization for PV integrated Building",2011 IEEE Trondheim Power Tech, Trondheim: Norvège (2011) [8] Riederer, Peter. (2005). "MATLAB/simulink for building and HVAC simulation - State of the art", IBPSA 2005 - International Building Performance Simulation Association 2005.

[9] Abarkan M. "Modélisation et Analyse du comportement d'un Bâtiment équipé d'un Système Multi Sources d'énergie", Thèse de doctorat. Université Sidi Mohamed Ben Abdellah, Fès, Maroc ;2014.

[10] Z. El Hariz and al. "Multi-Objective Optimal Control of Hybrid Energy System", International Journal of Renewable Energy Research, 2019; Vol.9, No.4.

[11] D. Farinet, M. Maurer, L. Vacca, S. V. Spataru and D. Stroe, "Battery Lifetime Analysis for Residential PV-Battery System used to optimize the Self Consumption - A Danish Scenario".2019 IEEE Energy Conversion Congress and Exposition (ECCE), Baltimore, MD, USA, 2019, pp. 6693-6698.

\section{Creative Commons Attribution License 4.0 (Attribution 4.0 International, CC BY 4.0)}

This article is published under the terms of the Creative Commons Attribution License 4.0 https://creativecommons.org/licenses/by/4.0/deed.en US 